Article

\title{
The Enduring Popularity of Legacy Journalism: An Analysis of Online Audience Data
}

\author{
Jacob L. Nelson \\ Walter Cronkite School of Journalism and Mass Communication, Arizona State University, Phoenix, AZ 85004, USA; \\ E-Mail: jacob.nelson.1@asu.edu
}

Submitted: 19 December 2019 | Accepted: 28 January 2020 | Published: 16 April 2020

\begin{abstract}
As news publishers continue to lose subscribers and advertising revenue, journalism practitioners and researchers have looked to newcomers to the field for ideas of how to adapt and succeed in a much more saturated and unstable media environment. Many have specifically looked to digital native news organizations to understand the ways that journalism is attempting to reinvent itself for a media landscape that is very different from the previous one. Yet what often gets lost in this focus on the newest news organizations is the resilience of many of journalism's older ones. In this study, I analyze a year's worth of U.S.-based online news consumption data to show that, even in a media environment increasingly saturated with digital native news outlets, legacy news brands continue to comprise a majority of the most popular news sites. Drawing on audience studies literature, I argue that these findings likely reflect audience preferences for familiar, established brands, as well as structural advantages these brands maintain due to their size and capital. I conclude that the fate of digital news organizations is not just a question of their innovativeness or nimbleness. It is also a question of their ability to combat a combination of powerful, stubborn forces: the habits of the people they hope to reach, and the deep pockets of their competitors.
\end{abstract}

\section{Keywords}

audience studies; digital native news; journalism; legacy news; news consumption; news publishers

\section{Issue}

This article is part of the issue "Digital Native News Media: Trends and Challenges" edited by Ramón Salaverría (University of Navarra, Spain).

(C) 2020 by the author; licensee Cogitatio (Lisbon, Portugal). This article is licensed under a Creative Commons Attribution 4.0 International License (CC BY).

\section{Introduction}

As news publishers continue to lose subscribers and advertising revenue, journalism practitioners and researchers have looked to newcomers to the field for ideas of how to adapt and succeed in a much more saturated and unstable media environment. Scholars study digital native news organizations to better understand the ways that journalism is attempting to reinvent itself for a very different media landscape than the previous one (Ferrucci, 2015, 2017; Nee, 2013). And industry stakeholders have pinned their hopes on digital native news publishers when it comes to solving the profession's most pressing problems. BuzzFeed, for exampleknown as one of the earliest and most successful digitally native news organizations-was described in 2015 as "the rare example of a news organization that changes the way the news industry works" and "the most influential news organization in America today" (LaFrance \& Meyer, 2015). As The Economist put it: "Great expectations attended digital journalism outfits. Firms such as BuzzFeed and Mashable were the hip kids destined to conquer the internet" ("Digital news outlets," 2017).

Indeed, when BuzzFeed laid off about 200 people in January of 2019, the widespread surprise and disappointment illustrated just how invested many throughout the profession had become in the notion that these digital-first news brands represented the guiding light in journalism's future. "The news," wrote David Uberti (2019) in Columbia Journalism Review, "cut deepest into the digital imagination." If BuzzFeed couldn't overcome the news industry's challenges, the conventional wisdom 
went, how did the rest of the profession stand a chance? As Farhad Manjoo (2019) put it in The New York Times: "Digital media needs a way to profitably serve the masses. If even BuzzFeed couldn't hack that, we are well and truly hosed."

Implicit in the discourse that emphasizes the potential of digital native news outlets is the assumption that legacy news outlets are already anachronistic. While digital native news brands represent the promise of the future, legacy news brands-those that began in radio, television, or print-represent a traditional approach to journalism that grows more conspicuously outdated as news consumption becomes more of a digital affair. Even as legacy news brands continue to publish the news, they are perceived as the way journalism once was, while digital native news publishers-defined by their focus first and foremost on publishing for the internet-represent the way it eventually will be. Yet this framing overlooks an important truth about the news media environment that this study seeks to bring to the fore: Legacy news publishers-not the digital natives-continue to attract the bulk of audience attention. In short, what gets lost in this focus on journalism's newest publishers is the resilience of many older ones.

In this study I analyze a year's worth of U.S.-based online news consumption data to show that, even in a media environment increasingly saturated with digital native news outlets, legacy news brands continue to comprise a majority of the most popular news sites. While a handful of digital native news organizations have broken through, most of those that continue to attract the largest number of readers comprise print, broadcast, and public radio brands, many of which were founded before the internet existed. Drawing on audience studies literature, I argue that these findings likely reflect audience preferences for familiar, popular brands, as well as structural advantages these brands maintain due to their size and capital. I conclude that the fate of digital news organizations is not just a question of their innovativeness or nimbleness. It is also a question of their ability to combat a combination of powerful, stubborn forces: the habits of the people they hope to reach, and the deep pockets of their competitors.

\section{Literature Review}

\subsection{The Advent-and Promise-of Digital Native News Publishers}

The advent of the internet brought with it a new form of news production: the digital native, or digital-born publication (Harlow \& Salaverría, 2016). Unlike legacy news outlets, which began before the internet and consequently privileged pre-internet mediums (e.g., broadcast, print, radio), digital native news organizations started with-and create news primarily for-online audiences. Indeed, many do not even have an offline edition (Majó-Vázquez, Nielsen, \& González-Bailón, 2019).
Similar to legacy news brands, digital native news outlets include generalist publications (e.g., BuzzFeed and Vice) that seek to emulate a traditional newspaper's coverage of a variety of topics (even if that coverage is produced and presented very differently) as well as outlets focused solely on more niche topics (e.g., criminal justice issues for The Marshall Project, music for Pitchfork).

Journalism research tends to distinguish between legacy and digital native news publishers for a number of reasons. Legacy news brands are typically larger and older than digital native news outlets, which makes comparing the two a useful way to examine the impact of size and institutional history on journalistic practice (Arrese \& Kaufmann, 2016; Ferrucci, 2015; Nelson, 2017). Patrick Ferrucci and Tim Vos (2017), for instance, explored how digital journalists conceptualize their own identities, in an effort to understand how this shift from print to online journalism is-and is not-changing how journalists approach their work. Conversely, Nikki Usher (2014) spent five months studying how employees at The New York Times were attempting to transition into a digital era. And Caitlin Petre (2015) did a comparison between the two groups, by analyzing how legacy journalists at the Times differed from digital native journalists at Gawker in their approaches to online audience metrics. Applying this distinction to analyses within journalism studies allows scholars to understand how newer and older news outlets are experimenting with different approaches to revenue - and to what end (Cornia, Sehl, \& Kleis Nielsen, 2019; Nee, 2014).

Consequently, comparing legacy and digital native news publishers allows scholars to uncover how attempts within journalism to adapt to an increasingly threatening news media environment are unfolding, as well as how those attempts differ from one kind of news publisher to another. Journalists at digital native news outlets tend to be perceived as less beholden to traditional journalistic practices, which means they arguably have more flexibility to experiment with different approaches to news production. Legacy news outlets, conversely, tend to be perceived as more resistant to change (Cornia et al., 2019). "When it comes to legacy news media and any new digital innovation, you can usually count on two things," reads a recent blog post published by the Reynolds Journalism Institute at the Missouri School of Journalism, "the innovation will begin too late, and even when it does, it's often a half-measure that doesn't make up lost time" (Brady, 2019). This is because, as Rebecca Coates Nee concluded in her comparison of legacy and digital native journalists, "online journalists view digital technology as an opportunity, not a threat to which they must adapt or react" (2013, p. 17).

The result of this assumed nimbleness on the part of digital natives is an implicit optimism when it comes to what digital natives might accomplish. This underlying confidence was apparent in the many news articles that expressed bewildered disappointment when, in early 2019, a number of digital native news organizations- 
including BuzzFeed, HuffPost, and Vice Media, laid off more than 1,000 employees. As Edmund Lee (2019) wrote in The New York Times:

The cuts at BuzzFeed were the most alarming. Wasn't this the company that was supposed to have it all figured out? Didn't its team of wizards, led by the M.I.T.trained chief executive, Jonah Peretti, know tricks of the digital trade that lay beyond the imagination of fusty old print publishers?

To be sure, there is evidence that suggests this optimism is to some degree warranted: Each year, many legacy news brands struggle to stay financially viable, while digital natives increase in number. There were 138 fewer daily newspapers in 2014 than there were in 2004, according to a recent report by Penny Abernathy (2016). This decrease was caused in part by some newspapers shutting down, and others getting bought and folded into existing brands. Both outcomes stem from the perpetual declines in profit and print readers, leading Abernathy (2016) to conclude that "every newspaper publisher is grappling with an uncertain future." Conversely, the number of employees working at digital natives nearly doubled between 2008 and 2018 (Pew Research Center, 2019). The excitement about digital native news organizations is not simply the result of a set of assumptions about what they might accomplish. It is also based in their increasing numbers and size, both of which suggest that the future of journalism and the future of digital native news publishers are inextricably linked.

However, this notion of digital natives as journalism's harbinger of the future and legacy news publishers as the profession's relics of the past implies an inaccurate understanding of how success and failure actually unfolds within the news media environment. The perspective that legacy brands are losing power and influence in an increasingly crowded news media landscape and are giving way to digital native news brands that will only grow more popular over time overlooks some of the most important-and enduring-characteristics that contribute to how audience attention gets concentrated within journalism. These characteristics notably have little to do with the work that news outlets actually produce, nor the nimbleness with which they produce it. In fact, these factors exist outside of any individual journalist's control, which means they often escape journalists' (and, consequently, journalism scholars') scrutiny. They include characteristics of the news audience, as well as the very structures within which the news media environment functions. It is these factors that I turn to next.

\subsection{An Audience Studies Approach to 'the Persistence of Popularity'}

Audience studies literature offers a number of explanations for what James Webster and Thomas Ksiazek (2012, p. 51) refer to as "the persistence of popularity" when it comes to media consumption. These include structuraland audience-specific factors that privilege the most familiar brands at the expense of everything else. First, audiences tend to equate popularity with quality (Salganik, Dodds, \& Watts, 2006). When it comes to journalism specifically, audiences perceive the popularity of a news story as evidence of both its accuracy and its importance (Asch, 1951; Mutz \& Young, 2011). This explains why, for example, when audiences seek out news, they privilege stories that have been "liked" or "favorited," or that have made a site's "most read" list (KnoblochWesterwick, Sharma, Hansen, \& Alter, 2005; Yang, 2015).

Additionally, audiences exhibit what Harsh Taneja, Angela Wu, and Stephanie Edgerly (2017) refer to as "infrastructural legacy," which they describe as a person's tendency to maintain media consumption routines across different media platforms. So, someone who reads The New York Times in print is likely to read it online, rather than seek out a new outlet for a different platform. This finding suggests that legacy brands in journalism are likely to maintain their audiences even as the number of digital native news outlets continues to grow-and even if those outlets provide journalism that more aligns with audience preferences. As Taneja et al. (2017, p. 1795) write, "Visiting sites with legacy status is more about established habits brought online and not specific preferences for content."

There are also a number of structural forces within the news media environment that further encourage audiences to maintain their concentration among a small number of already popular brands. The social media platforms that people increasingly turn to for news, for instance, tend to rely on algorithms that privilege popularity above other characteristics (Bucher, 2017; Carlson, 2017). This means that a news story from a familiar brand (e.g., The Washington Post) is more likely to get pushed into audiences' newsfeeds than the same story from a newer, lesser known outlet (Nelson, 2019). A digital native news outlet therefore faces an uphill battle to build its popularity so that its content can enjoy these sorts of advantages enjoyed by its older, more established competitors.

The most successful legacy news brands also benefit from a media environment that offers outlets with deep pockets a variety of means by which to expand their reach. As Matthew Hindman (2018) writes, the internet has not lowered the costs of media distribution-it has simply changed what those costs entail. News brands that have been around for a long time and have more capital to draw from (e.g., The New York Times, The Wall Street Journal) are able to invest more money into expensive techniques intended to increase the scope of their distribution than many of their smaller, newer competitors. These techniques include A/B headline testing (Bulik, 2016), as well as the personalization of news (Thurman, Moeller, Helberger, \& Trilling, 2018). As a result of these distribution advantages, Hindman concludes that "big sites can dominate even if smaller sites 
produce better content that perfectly matches users' preferences" (2018, p. 8).

To be sure, in addition to these distribution advantages, many legacy brands also benefit from an important production benefit as well: They have the means to invest in a larger amount of original reporting than many of the digitally native startups they are competing against. The Washington Post, for example, publishes about 500 stories per day (Meyer, 2016). LevittownNow.com, a small, digitally native local news site based in Pennsylvania, publishes about 50 stories per week. The New York Times employs 1,600 journalists, while The Marshall Project employs roughly 20. So, it is not just the structures behind digital distribution that favor legacy brands, but their ability to produce news that is distinctive, and at scale, as well.

In light of this literature, as well as previous studies that have found that media audiences continue to congregate among the most popular, established brands, the promise of digital native news publishers to forge the path forward for journalism becomes a bit less persuasive. These outlets may boast more experimental approaches to news production, making them perhaps quicker to adapt to an increasingly unstable news media environment. They may also produce news that are better attuned to the desires of the online audiences they have decided to pursue. But even if those two things were true, they would not necessarily guarantee that digital native news outlets would consequently attract larger audiences than the legacy news brands many believe they will soon overshadow. Instead, it would appear more likely that, even in a media environment with many digital native news outlets, the most popular will continue to be legacy brands that many are already familiar with. With that, my hypothesis is as follows:

$\mathrm{H} 1$ : In a saturated news media environment, audience attention continues to be concentrated among established, legacy news brands.

\section{Method}

\subsection{Data}

My data come from Comscore, a media and audience measurement company that reports monthly estimates of online audience behavior. I was granted access to Comscore's data through a subscription paid for by my university. Scholars have previously used Comscore data to study a variety of aspects of news audience behavior. These include fake news consumption (Allcott \& Gentzkow, 2017; Nelson \& Taneja, 2018), mobile news consumption (Nelson, 2019; Nelson \& Lei, 2018), political news consumption (Gentzkow \& Shapiro, 2011; Nelson \& Webster, 2017), and audience engagement with news (Nelson \& Webster, 2016).

One of the biggest assets of audience measurement data provided by companies such as Comscore is the way in which these data are collected. Comscore data are actual observations of audience behavior, rather than selfreports collected via surveys or interviews. This methodological distinction is valuable because audiences often misremember or exaggerate their news media consumption (Prior, 2009), a tendency that scholars have found is even more extreme in today's seemingly endless media landscape (Taneja, Webster, Malthouse, \& Ksiazek, 2012). Audience measurement data providers are able to sidestep these methodological issues. Instead, these firms collect their audience data using software installed on a person's digital device that automatically records their media behavior (Taneja, 2016). This passive data collection results in a more precise record of news audience behavior.

As previous studies have explained, Comscore collects data: (1) from its panels of mobile device and desktop computer users; and (2) from online publishers who place Comscore tags on their websites (Nelson, 2019). These tags give Comscore the ability to observe and record each instance in which audiences access these publishers' content, while Comscore's panels give Comscore the ability to validate that the online behavior recorded by the tags is consistent with the actual online audience. After Comscore collects these data, the company runs data cleansing and validation processes, which results in a dataset of online usage data divided by site.

Comscore collects data about digital audience behavior from around the world; however, this study focuses on Comscore's U.S. dataset. As previous studies that have drawn from Comscore's U.S. data have noted (Nelson, 2019), the company's desktop panel comprises about 1 million people, who load Comscore meters onto their desktop devices. Comscore's U.S. mobile panel includes about 30,000 people across iPhones, iPads, and Android devices. Similar to the desktop panelists, the mobile panelists download a meter onto their devices that monitors their online behavior. Comscore's meter tracks the URLs that each user visits, as well as the time they spend looking at each address. These panels are then weighted and projected to the U.S. online audience at large. Comscore then uses the data collected from these panels to create a projection of de-duplicated multi-platform usage. Doing so ensures that panelists who visit a news site on a mobile device and then the same site on a desktop computer are still only counted as one visitor to the site, rather than two.

Comscore recruits people 18 and older to join its mobile and desktop panels. To do so, the company uses online market research firms such as PermissionResearch and OpinionSquare. Comscore panelists are offered various benefits to participate, including opportunities to win money, donate to charity, or participate in an online rewards program. For the desktop panel, which may include one computer shared among multiple family members, Comscore employees further examine these visitation data to assign different online behaviors to different household members. 
Comscore publishers can create hierarchies of their owned and operated websites and mobile apps, which allows these publishers to observe the full, unduplicated reach across their inventory of websites and apps. Comscore also classifies websites into categories, such as education, sports, and retail. This study's sample comprised the websites within Comscore's "News" category. As Nelson observed in a previous study drawn from Comscore data (2019), the company has a minimum reporting threshold for any one entity to be reported in a given month. Consequently, the number of reportable entities can vary from month to month.

In this analysis, the number of News/Information web entities analyzed included 1,645 entities in the multi-platform dataset. These sites included legacy news brands (e.g., The New York Times, The Washington Post), digital native news outlets (e.g., BuzzFeed, Vox), in addition to a wide variety of other kinds of news producers, such as partisan media (e.g., MSNBC, Drudge Report), local news sources (e.g., Philly.com, Las Vegas Review), and sources for information about the weather (e.g., The Weather Company, AccuWeather).

\subsection{Analysis}

To examine the size of the audiences to legacy and digital native news sites, I utilized Comscore's measure of 'unique visitors.' This metric refers to a person who visited a site at least once in a given month. The unique visitor metric is one of the most commonly used within the digital media industry to evaluate audience reach (Nelson, 2019). That said, it is not a flawless metric: Users who clear cookies or browse in "private" or "incognito" mode can distort counts of the actual online audience to the point where "the unique-visitor-to-actual-person ratio is four to one or higher on many sites" (Hindman, 2018, p. 107). However, Comscore collects its data from both its panel as well as browser cookies, which means that the company's datasets "should not suffer from the overcounting of audience reach endemic to other data sources" (Hindman, 2018, p. 107).

I compiled a Comscore dataset that comprised the distribution of multi-platform unique visitors to all of the sites within the news category each month between September 2018 and September 2019. My analysis began by examining a random month within the sample to observe whether or not online audiences followed an "80/20 power law distribution" (Webster, 2014) where the majority of the audience's attention would be focused among a small number of highly popular news outlets. After I observed that this audience distribution was indeed the case, I calculated the averages of unique visitors to the news sites within my dataset between September 2018 and September 2019 to ensure that this distribution held true over time.

Once it was apparent that audiences were indeed congregating among a small number of the most popular news sites within the dataset both within an individ- ual month as well as over time, I narrowed my analysis to the top 100 sites where the bulk of that audience attention was concentrated. A research assistant and I then independently coded each of these sites to determine which were "legacy" news brands-meaning they were originally founded for a non-digital platform - and which were "digital native" news brands-meaning they were originally founded for the internet. Our intercoder reliability was 0.92 . I then calculated the percentage of legacy news sites these 100 most popular news sites comprised as well as the percentage of digital native news sites.

I concluded my analysis by performing a Point-Biserial Correlation on these 100 sites to observe whether a news site being a legacy brand was significantly related to its popularity (measured by unique visitors). Point-Biserial Correlations are used when correlating a dichotomous variable with a continuous variable. In this instance, the dichotomous variable was whether or not a news site is a legacy brand, while the continuous variable was the audience size. Point-Biserial Correlations follow the same assumptions as Pearson correlations.

\section{Results}

I began by examining the distribution of the online audience across news sites in March 2019. The data indeed revealed an 80/20 power law distribution. Although there was a long tail of online news sites within the dataset, the bulk of the online audience was concentrated at the head (Figure 1). For example, of the 232 million people who visited a news site in March 2019, about 146 million visited CNN, about 142 million visited Yahoo-HuffPost, and about 132 million visited USA Today. Each of these were among the top ten most popular sites, which also included NBC News, The Weather Company, Fox News, The New York Times, and The Washington Post. Conversely, only 35,000 people visited MinnPost.com, which ranked 703rd in unique visitors in March 2019.

Next, I calculated the averages of unique visitors to the news sites within my dataset between September 2018 and September 2019. I found that audience attention maintained the same power law distribution, again with the bulk of the audience concentrated at the head of the long tail (Figure 2).

Once it was clear that audience attention was skewed to the head of the long tail, I narrowed my dataset to the 100 most popular news sites and, with the help of a research assistant, determined which sites were legacy and which were digital native news brands. I found that, of the 100 most popular news sites, 66 were legacy news brands, while the remaining 34 were digital native news brands. Furthermore, of the 10 most popular news sitesthe only sites in the sample to attract, on average, roughly 100 million visitors each month-six were legacy news brands, while the remaining four were digital natives.

Finally, I performed a Point-Biserial Correlation on these 100 sites to observe whether a news site being a legacy brand was significantly related to its popular- 


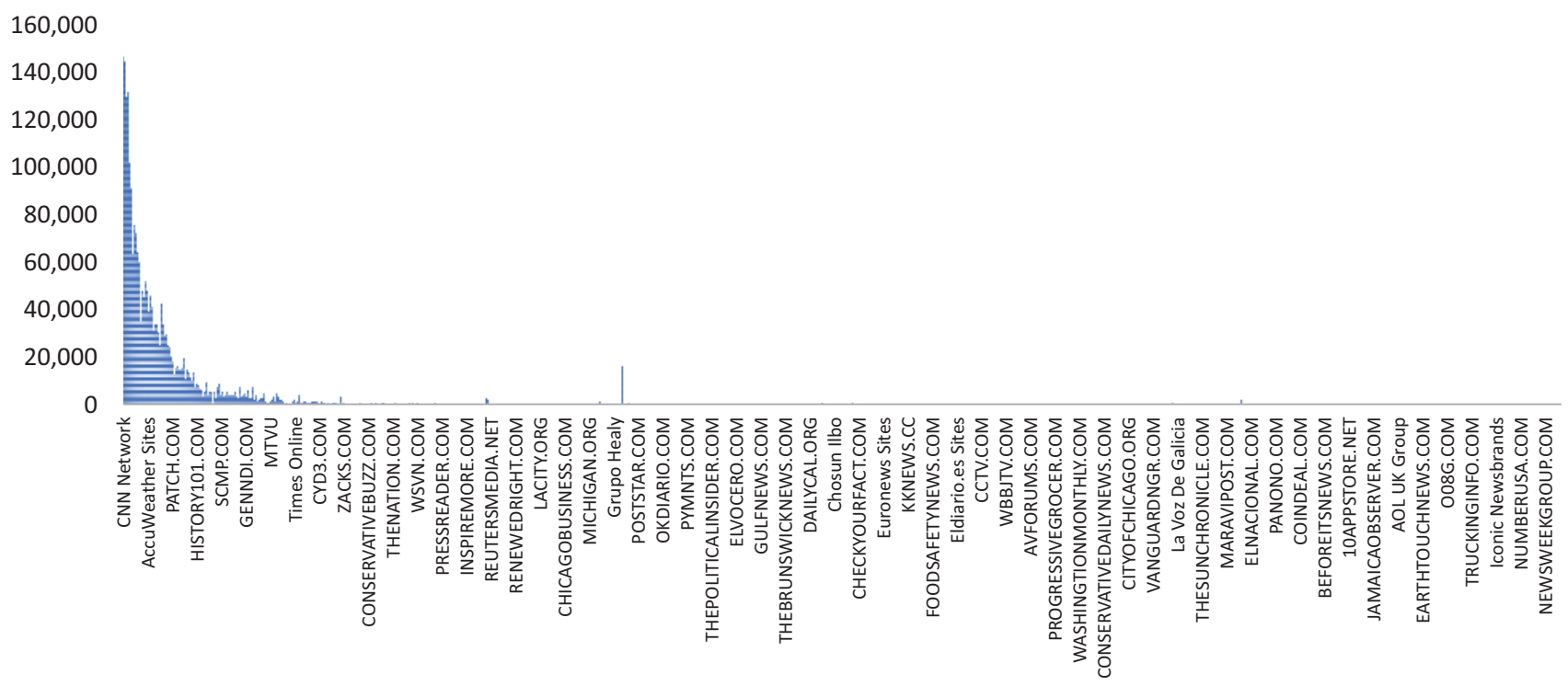

Figure 1. The online audience distribution to news sites in March 2019, measured in unique visitors (in thousands).

ity. I found that the relationship between these two variables was weak (0.08) and not statistically significant $(p=0.43)$. So, while the most popular news sites among audiences includes many legacy news brands, there was no statistical reason to expect that one must follow the other.

\section{Discussion}

\subsection{Studying What Changes-And What Endures}

Because so much within the news media environment appears to be in a perpetual state of transition, it is reasonable to wonder what about the profession has held constant, if anything. Audiences once deliberately consumed news via print papers or television broad- casts, but now do so "incidentally" while scanning social media newsfeeds on their mobile devices (Boczkowski, Mitchelstein, \& Matassi, 2018; Fletcher \& Nielsen, 2018). News publishers once targeted homogenous, mass audiences, but now increasingly rely on sophisticated audience data to focus specifically on distinct groups (Nelson, 2017; Nelson \& Tandoc Jr., 2018). And the advertisingsupported revenue model continues to show signs that it alone cannot be counted on to keep news organizations financially stable (Braun \& Eklund, 2019), which has compelled many of them to look to alternative means, such as subscriptions, donations, native advertising, and foundation support (Amazeen \& Wojdynski, 2018; Ferrucci \& Nelson, 2019; Hansen \& Goligoski, 2018; Moritz, 2018). Even digital outlets like BuzzFeed, which became renowned for appearing to crack the code to economic

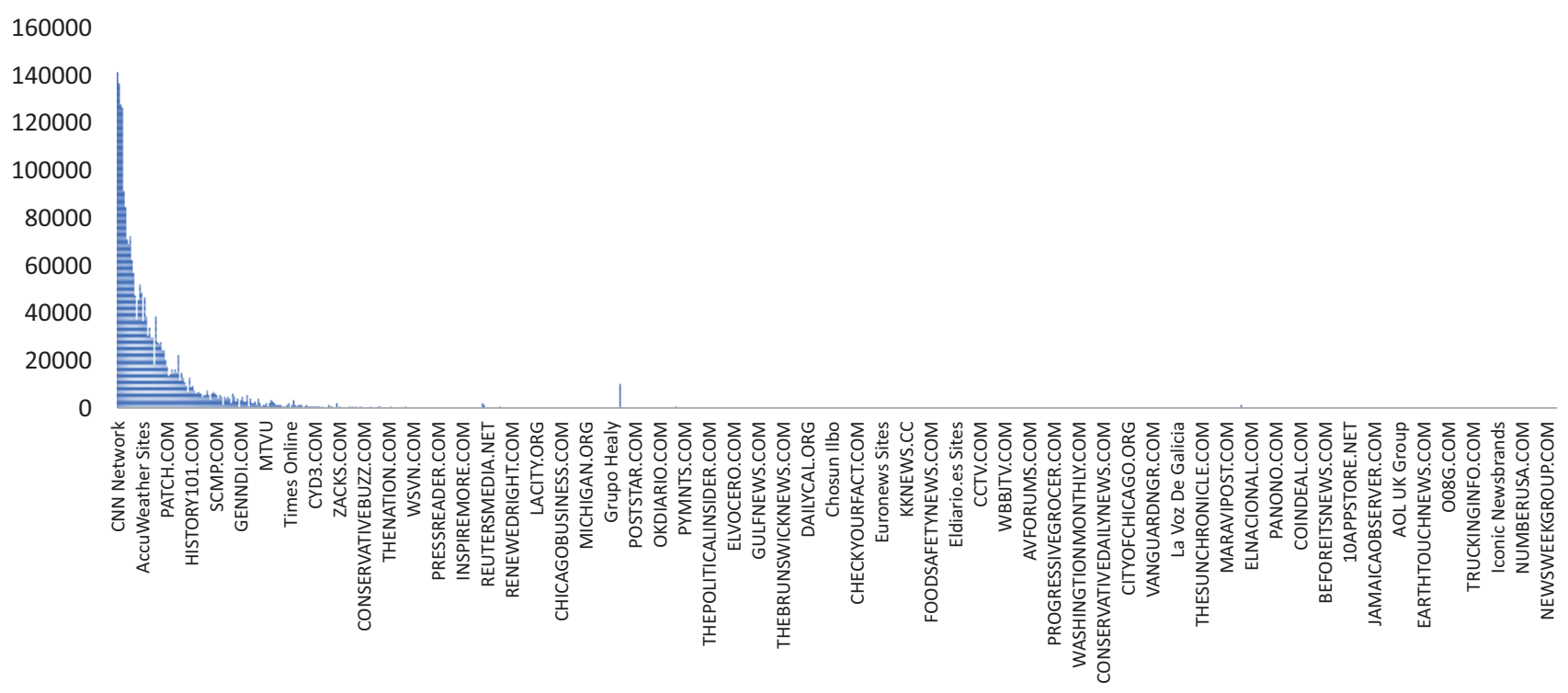

Figure 2. The average online audience distribution to news sites between September 2018 and September 2019, measured in unique visitors (in thousands). 
160000

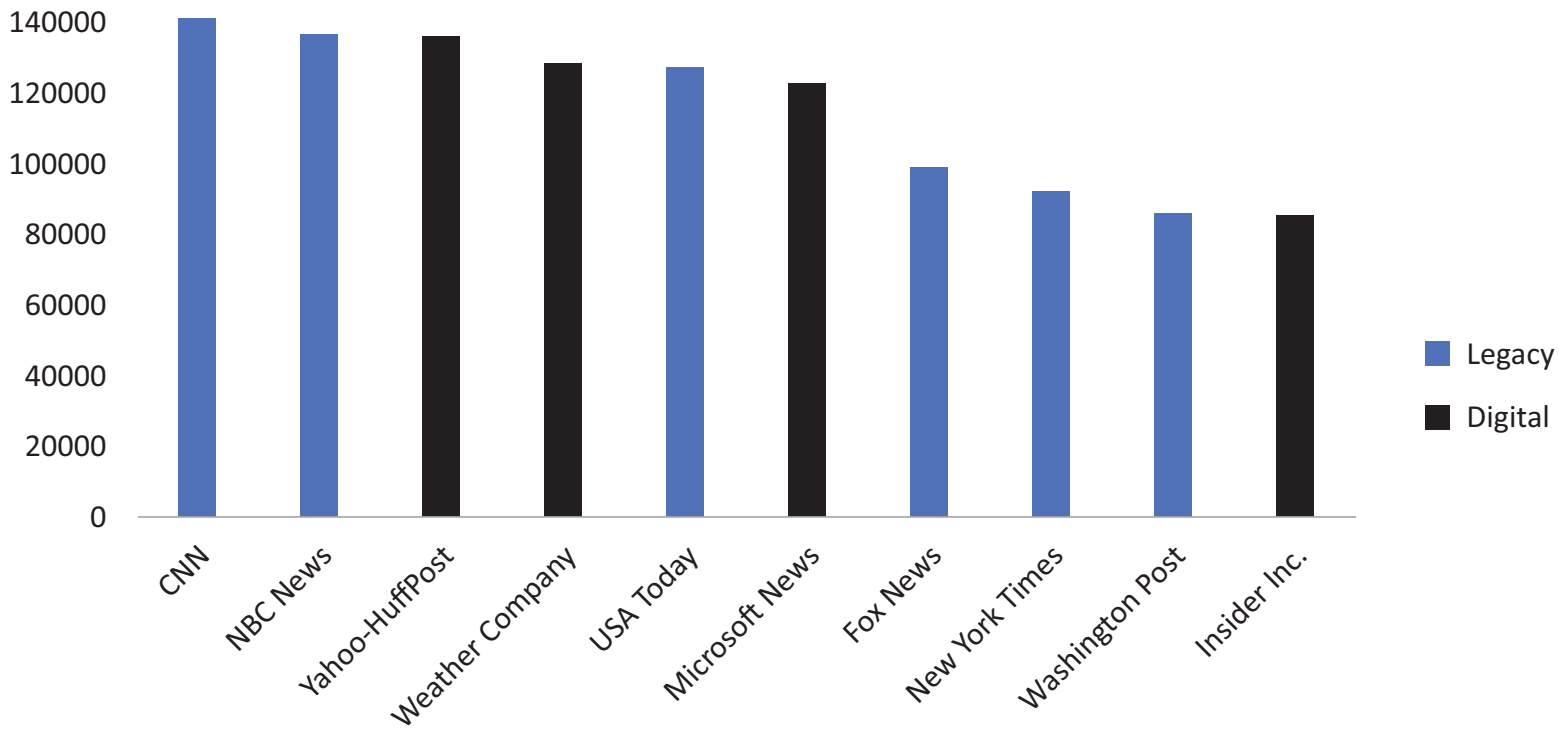

Figure 3. The average online audience for the most popular news sites in the dataset between September 2018 and September 2019, measured in unique visitors (in thousands).

sustainability via digital advertising revenue, has recently begun experimenting with audience-supported revenue via its paid membership program (Schmidt, 2018). These are significant changes and have rightfully garnered a great deal of scrutiny from journalism researchers and practitioners alike.

However, focusing primarily on what changes within journalism runs the risk of overlooking what remains the same: namely, where audiences actually turn to for news. As these findings demonstrate, even in an increasingly saturated news media environment, audiences continue to concentrate their attention within a small number of news outlets, the bulk of which comprises familiar, established brands. The evidence presented here joins a growing list of scholarship that corroborates the notion that news media routines are much more rigid than many might expect. Contrary to fears of "filter bubbles" (Pariser, 2011), scholars have found that when it comes to political news consumption, fake news consumption, and mobile news consumption, audiences tend to skew toward a small number among well-known, popular news brands (Nelson, 2019; Nelson \& Taneja, 2018; Nelson \& Webster, 2017). The result is the perpetuation of a "winner takes all" media environment, or what Webster (2014) refers to as the "massively overlapping culture," where a majority of the media audience continues to devote its attention to a small number of familiar, established brands. As Nelson $(2019$, p. 2) recently concluded, "It seems no matter how long the long tail grows, audiences are still reluctant to venture far from its head."

\subsection{Limitations}

This study faced several limitations, the most significant of which was the inability to take a more longitudinal approach to the data analysis. Although the Comscore dataset included a year's worth of online visitation data, it did not allow for a comparison of that year's data with the years before. Also, these data were outlet-specific, meaning I was only able to analyze news audiences who decided to visit a specific news organization's website. This means I could not examine news exposure that took place passively (or "incidentally") via social media, an increasingly popular mode of news consumption (Fletcher \& Nielsen, 2018; Newman, Fletcher, Kalogeropoulos, \& Nielsen, 2019; Thorson \& Wells, 2016). However, while the news consumption behavior exhibited by those who passively consume news via social media might be very different from those who actively load pages for specific news outlets, it is more likely that both groups stumble onto many of the same sources of information, but only one group decides to click.

Furthermore, these data were platform-specific. While I could see how many people visited legacy and digital-native news outlets online, I could not compare those data with data showing how many people watched, listened to, or read those legacy news outlets on the mediums they perhaps originally focused on. However, since the purpose of this study was to explore whether or not the popularity of legacy news brands has endured in an online environment, as well as to compare the popularity of legacy news brands with that of digital native news brands, the online-specific data offered by Comscore was the most useful kind to draw from.

Another limitation of this study is that while its analysis focused on measures of popularity within the digital news media landscape, it did not touch on the relationship between each news outlet's popularity and its revenue model. This is worth acknowledging at a moment when the news industry finds itself increas- 
ingly in agreement that digital advertising revenuewhich privileges audience reach above all else-cannot alone sustain a news outlet (Chyi \& Tenenboim, 2019; Thompson, 2018). In light of the layoffs at BuzzFeed, for example, there was widespread consensus that the cuts were due in part to the company's dependence on digital ad revenue and its reluctance to embrace paywalls or other forms of audience support (Lee, 2019; Uberti, 2019). While this approach to revenue appeared at least somewhat viable in the early 2000s, it has faltered more recently due to the consolidation of online advertising among Google, Amazon, and Facebook (Nielsen, Cornia, \& Kalogeropoulos, 2016). As Kate Knibbs (2019) wrote in The Ringer, "Facebook and Google's emergence as publisher-platforms with near-unfettered power has cratered the advertiser-supported model." So, while a news site like Yahoo-HuffPost News Network may attract a hundred million more unique visitors than The Wall Street Journal in a given month, the latter-due to its long-standing paywall-might actually be the more sustainable of the two organizations.

Consequently, assuming newsrooms continue to look toward paywalls, subscriptions, memberships, and other forms of audience-supported revenue, they may focus less on amassing the largest audience and more on attracting the most loyal one. Should that indeed be the case, it will become increasingly important to understand a news outlet's path to revenue when analyzing the implications of the size of its audience. This gets to the final limitation of this study, which is that its focus on measures of popularity runs the risk of conflating the aspirations of legacy news brands with those of digitally native news outlets. Although journalism stakeholders have looked to digitally native news startups to pave the path for journalism's future, they have not necessarily done so with the expectation that these outlets would match or exceed legacy outlets in terms of overall audience reach. This makes sense given the different approaches to success typically pursued by legacy news brands as compared to digitally native ones.

Indeed, the idea of bundling a variety of subjects within one overarching media brand-long embraced by daily newspapers-appears to have been all but discarded by many digitally native news outlets. They instead seem to be attempting to compete with legacy outlets within specific verticals (e.g., technology, entertainment, criminal justice). So, for example $N B C$ News Digital-one of the most popular brands among online news audiences, according to the Comscore data-comprises more than three hundred different verticals, including those for local news stations (NBC Philadelphia, NBC Miami), political news (MSNBC, NBC News Politics), and entertainment news (E! News, Today Pop Culture). Conversely, less popular, digital native brands like Gizmodo comprise only one. This distinction is indicative of the fact that the economics for digital native news outlets are different, and so their missions have been different from the outset.
Yet despite the fact that legacy and digital native news sites have such different compositions and goals, there is still much to be gained from this sort of comparison between the two. After all, every news site participates in the same competition for audience attention, regardless of the breadth or variety of its offerings. Of course, while this study has taken an initial step toward understanding how this competition unfolds in an online environment, there is much more to be done. Future research should examine the relationship between the amount of audience attention an outlet attracts with other variables that play pivotal roles in determining whether that outlet succeeds or fails: the scope of its coverage, the scale of its operation, and the approach it takes to monetization.

\section{Conclusion}

These findings are significant for a number of reasons. First, by presenting a more accurate portrait of how online audiences actually consume news, these results indicate just how challenging it is for digital news providers just starting out to break into the news media landscape and build up an audience. One might think that digital native news outlets would enjoy greater advantages when it comes to finding audiences on the internet, since it is a medium that they have focused on since their inception. However, the fact that so many of the most popular online news sites are owned by brands in news that began with television, print, or radio suggests that any sort of internet savvy that digital native news publishers enjoy may not be enough to overcome the advantages held by more longstanding brands in news. On the contrary, as Hindman (2018) has pointed out, these results indicate that digital native news sites within the news media environment face significant disadvantages that must be overcome-namely, onerous distribution costs, stubborn audiences, and social media platforms primed to privilege the familiar over the novel. Rather than make the internet more democratic and egalitarian, all of these challenges are likely to exacerbate an already highly unequal playing field.

To be sure, the fact that about a third of the 100 most popular news sites were digital natives, combined with the fact that there was not a strong correlation between the popularity of a news site and its status as a legacy news brand, indicates that while the distribution of audience attention across the news media environment may be slow to change, it certainly is not fixed. The successful capture of audience attention, however, is far from guaranteed, especially for news outlets that lack the same level of capital and brand-recognition as their established competitors.

Furthermore, the increasing amount of consolidation within the news media environment will likely lead to even greater disparity between the most and least popular brands. In 2019, New Media Investment Group merged with Gannett, making it the largest newspaper company in the U.S. (Tracy, 2019). The new Gannett now 
owns more than 20 percent of all U.S. daily newspapers (Doctor, 2020). And consolidation is not only affecting legacy brands, but digital natives as well: for example, Yahoo and HuffPost merged in 2017. In March 2019, according to the Comscore data, the Yahoo-HuffPost News Network had 416 different verticals. These developments indicate that as more news providers get purchased by or merge with larger entities, we are likely to see further audience concentration among an even smaller number of brands.

In short, the path toward financial stability in journalism is unlikely to be trailed solely by digital native news outlets. Instead, in an increasingly hostile news media environment, these findings suggest that different journalism stakeholders are embracing different approaches to success. Some are attempting to emulate the traditional model of bundling verticals with the hopes of garnering a greater portion of audience. Others are pursuing financial stability by finding success on a smaller scale-through specialized, limited coverage intended for niche audiences. As Rasmus Kleis Nielsen (2019) wrote recently:

Many trying to make the transition from offline to online will not succeed. Often, those trying to build something new will fail. Some of those who succeed will still fall short of their hopes and aspirations. Very few will generate anything like the revenues or profits we saw in the past. But more and more are finding their own ways forward, on that basis they will be able to do important, independent, journalistic work, and we should recognize and celebrate that.

Understanding the obstacles that stand in the way of success in today's news media environment, and their disparate impact on those attempting success, is an important step toward determining how the news media landscape will continue to change-and how it will not. As this study has shown, only by complementing studies of what changes with examinations of what endures will we understand how transformation actually unfolds within the news media environment, as well as the implications of both for those who publish the news and the people they hope to reach.

\section{Acknowledgments}

The author wishes to thank the reviewers for their thoughtful, thorough, and constructive feedback.

\section{Conflict of Interests}

The author declares no conflict of interests.

\section{References}

Abernathy, P. M. (2016). The rise of a new media baron and the emerging threat of news deserts. Chapel Hill,
NC: Center for Innovation and Sustainability in Local Media.

Allcott, H., \& Gentzkow, M. (2017). Social media and fake news in the 2016 election. Journal of Economic Perspectives, 31(2), 211-236. https://doi.org/10.1257/ jep.31.2.211

Amazeen, M. A., \& Wojdynski, B. W. (2018). The effects of disclosure format on native advertising recognition and audience perceptions of legacy and online news publishers. Journalism. Advance online publication. https://doi.org/10.1177/1464884918754829

Arrese, Á., \& Kaufmann, J. (2016). Legacy and native news brands online: Do they show different news consumption patterns? JMM International Journal on Media Management, 18(2), 75-97. https://doi. org/10.1080/14241277.2016.1200581

Asch, S. (1951). Effects of group pressure upon the modification and distortion of judgment. Journal of Social Psychology, 12, 433-465.

Boczkowski, P. J., Mitchelstein, E., \& Matassi, M. (2018). "News comes across when I'm in a moment of leisure": Understanding the practices of incidental news consumption on social media. New Media and Society, 20(10), 3523-3539. https://doi.org/ 10.1177/1461444817750396

Brady, J. (2019). There's a reader revenue revolution happening: Will legacy news miss it-Again? Reynolds Journalism Institute. Retrieved from https://www.rjionline.org/stories/theres-a-readerrevenue-revolution-happening.-will-legacy-newsmiss-it-agai

Braun, J. A., \& Eklund, J. L. (2019). Fake news, real money: Ad tech platforms, profit-driven hoaxes, and the business of journalism. Digital Journalism, 7(1), 1-21. https://doi.org/10.1080/21670811.2018.1556314

Bucher, T. (2017). The algorithmic imaginary: Exploring the ordinary affects of Facebook algorithms. Information, Communication \& Society, 20(1), 30-44. https:// doi.org/10.1080/1369118X.2016.1154086

Bulik, M. (2016, June 13). Which headlines attract most readers? The New York Times. Retrieved from https://www.nytimes.com/2016/06/13/insider/ which-headlines-attract-most-readers.html

Carlson, M. (2017). Facebook in the news. Digital Journalism, 6(1), 4-20. https://doi.org/10.1080/21670811. 2017.1298044

Chyi, H. I., \& Tenenboim, O. (2019). From analog dollars to digital dimes: A look into the performance of US newspapers. Journalism Practice, 13(8), 988-992. https://doi.org/10.1080/17512786.2019.1642793

Cornia, A., Sehl, A., \& Kleis Nielsen, R. (2019). Comparing legacy media responses to the changing business of news: Cross-national similarities and differences across media types. International Communication Gazette, 81(6/8), 686-706. https://doi.org/ $10.1177 / 1748048518808641$

Digital news outlets are in for a reckoning. (2017). The Economist. Retrieved from https://www. 
economist.com/business/2017/11/30/digital-newsoutlets-are-in-for-a-reckoning

Doctor, K. (2020). Newsonomics: Here are 20 epiphanies for the news business of the 2020s. Nieman Lab. Retrieved from https://www.niemanlab.org/2020/ 01/newsonomics-here-are-20-epiphanies-for-thenews-business-of-the-2020s

Ferrucci, P. (2015). Public journalism no more: The digitally native news nonprofit and public service journalism. Journalism, 16(7), 904-919. https://doi.org/ $10.1177 / 1464884914549123$

Ferrucci, P. (2017). Exploring public service journalism: Digitally native news nonprofits and engagement. Journalism and Mass Communication Quarterly, 94(1), 355-370. https://doi.org/10.1177/ 1077699016681968

Ferrucci, P., \& Nelson, J. L. (2019). The new advertisers: How foundation funding impacts journalism. Media and Communication, 7(4), 45-55. http://dx.doi.org/ 10.17645/mac.v7i4.2251

Ferrucci, P., \& Vos, T. (2017). Who's in, who's out? Constructing the identity of digital journalists. Digital Journalism, 5(7), 868-883. https://doi.org/10.1080/ 21670811.2016.1208054

Fletcher, R., \& Nielsen, R. K. (2018). Are people incidentally exposed to news on social media? A comparative analysis. New Media and Society, 20(7), 2450-2468. https://doi.org/10.1177/14614448177 24170

Gentzkow, M., \& Shapiro, J. M. (2011). Ideological segregation online and offline. Quarterly Journal of Economics, 126(4), 1799-1839. https://doi.org/ 10.1093/qje/qjr044

Hansen, E., \& Goligoski, E. (2018). Guide to audience revenue and engagement. New York, NY: Tow Center for Digital Journalism, Columbia University. Retrieved from https://www.cjr.org/tow_center_reports/ guide-to-audience-revenue-and-engagement.php

Harlow, S., \& Salaverría, R. (2016). Regenerating journalism: Exploring the "alternativeness" and "digitalness" of online-native media in Latin America. Digital Journalism, 4(8), 1001-1019. https://doi.org/ 10.1080/21670811.2015.1135752

Hindman, M. S. (2018). The Internet trap: How the digital economy builds monopolies and undermines democracy. Princeton, NJ: Princeton University Press.

Knibbs, K. (2019). BuzzFeed layoffs are a bad sign for online news. The Ringer. Retrieved from https:// www.theringer.com/tech/2019/1/26/18198621/ buzzfeed-news-layoffs-digital-media-economy

Knobloch-Westerwick, S., Sharma, N., Hansen, D. L., \& Alter, S. (2005). Impact of popularity indications on readers' selective exposure to online news. Journal of Broadcasting \& Electronic Media, 49(3), 296-313. https://doi.org/10.1207/s15506878jobem4903_3

LaFrance, A., \& Meyer, R. (2015). The eternal return of BuzzFeed. The Atlantic. Retrieved from https:// www.theatlantic.com/technology/archive/2015/04/ the-eternal-return-of-buzzfeed/390270

Lee, E. (2019, February 1). Digital media: What went wrong. The New York Times. Retrieved from https:// www.nytimes.com/2019/02/01/business/media/ buzzfeed-digital-media-wrong.html

Majó-Vázquez, S., Nielsen, R. K., \& González-Bailón, S. (2019). The backbone structure of audience networks: A new approach to comparing online news consumption across countries. Political Communication, 36(2), 227-240. https://doi.org/10.1080/ 10584609.2018.1546244

Manjoo, F. (2019, January 30). Why the latest layoffs are devastating to democracy. The New York Times. Retrieved from https://www.nytimes.com/2019/01/ 30/opinion/buzzfeed-layoffs.html

Meyer, R. (2016). How many stories do newspapers publish per day? The Atlantic. Retrieved from https:// www.theatlantic.com/technology/archive/2016/05/ how-many-stories-do-newspapers-publish-per-day/ 483845

Moritz, B. (2018). The subscription-pocalypse is about to hit. Nieman Lab. Retrieved from http:// www.niemanlab.org/2018/12/the-subscriptionpocalypse-is-about-to-hit

Mutz, D. C., \& Young, L. (2011). Communication and public opinion. Public Opinion Quarterly, 75(5), 1018-1044. https://doi.org/10.1093/poq/nfr052

Nee, R. C. (2013). Creative destruction: An exploratory study of how digitally native news nonprofits are innovating online journalism practices. JMM International Journal on Media Management, 15(1), 3-22. https://doi.org/10.1080/14241277.2012.732153

Nee, R. C. (2014). Social responsibility theory and the digital nonprofits: Should the government aid online news startups? Journalism, 15(3), 326-343. https:// doi.org/10.1177/1464884913482553

Nelson, J. L. (2017). And deliver us to segmentation. Journalism Practice, 12(2), 204-219. https://doi.org/ 10.1080/17512786.2017.1378588

Nelson, J. L. (2019). The persistence of the popular in mobile news consumption. Digital Journalism, 8(1), 87-102. https://doi.org/10.1080/21670811. 2019.1612766

Nelson, J. L., \& Lei, R. F. (2018). The effect of digital platforms on news audience behavior. Digital Journalism, 6(5), 619-633. https://doi.org/10.1080/ 21670811.2017.1394202

Nelson, J. L., \& Tandoc, E. C., Jr. (2018). Doing "well" or doing "good": What audience analytics reveal about journalism's competing goals. Journalism Studies, 20(13), 1960-1976. https://doi.org/ 10.1080/1461670X.2018.1547122

Nelson, J. L., \& Taneja, H. (2018). The small, disloyal fake news audience: The role of audience availability in fake news consumption. New Media \& Society, 20(10), 3720-3737. https://doi.org/10.1177/ 1461444818758715

Nelson, J. L., \& Webster, J. G. (2016). Audience curren- 
cies in the age of big data. JMM International Journal on Media Management, 18(1), 9-24. https://doi.org/ $10.1080 / 14241277.2016 .1166430$

Nelson, J. L., \& Webster, J. G. (2017). The myth of partisan selective exposure: A portrait of the online political news audience. Social Media + Society, 3(3), 2056305117729314. https://doi.org/10.1177/ 2056305117729314

Newman, N., Fletcher, R., Kalogeropoulos, A., \& Nielsen, R. K. (2019). Reuters Institute digital news report 2019. Oxford: Reuters Institute for the Study of Journalism. Retrieved from https://reutersinstitute. politics.ox.ac.uk/sites/default/files/2019-06/DNR_ 2019_FINAL_0.pdf

Nielsen, $\bar{R}$. K. (2019). The business we want, not the business we had. Nieman Lab. Retrieved from https://www.niemanlab.org/2019/12/the-businesswe-want-not-the-business-we-had

Nielsen, R. K., Cornia, A., \& Kalogeropoulos, A. (2016). Challenges and opportunities for news media and journalism in an increasingly digital, mobile, and social media environment. Oxford: Reuters Institute for the Study of Journalism. Retrieved from https:// tinyurl.com/vst7m63

Pariser, E. (2011). The filter bubble: What the Internet is hiding from you. New York, NY: Penguin Press.

Petre, C. (2015). The social life of metrics: The production, interpretation, and use of data analytics in online journalism (Unpublished Doctoral dissertation). NYU Department of Sociology, New York, NY, USA.

Pew Research Center. (2019). Digital news fact sheet. Pew Research Center. Retrieved from https://www. journalism.org/fact-sheet/digital-news

Prior, M. (2009). The immensely inflated news audience: Assessing bias in self-reported news exposure. Public Opinion Quarterly, 73(1), 130-143. https://doi.org/ $10.1093 / \mathrm{poq} / \mathrm{nfp002}$

Salganik, M. J., Dodds, P. S., \& Watts, D. J. (2006). Experimental study of inequality and unpredictability in an artificial cultural market. Science, 311(5762), 854-856. https://doi.org/10.1126/science.1121066

Schmidt, C. (2018). What does membership mean for BuzzFeed news: At a company that's already raised nearly $\$ 500$ million in venture capital? Nieman Lab. Retrieved from https://www.niemanlab.org/2018/ 12/what-does-membership-mean-for-buzzfeednews-at-a-company-thats-already-raised-nearly500-million-in-venture-capital
Taneja, H. (2016). Using commercial audience measurement data in academic research. Communication Methods and Measures, 10(2/3), 176-178. https:// doi.org/10.1080/19312458.2016.1150971

Taneja, H., Webster, J. G., Malthouse, E. C., \& Ksiazek, T. B. (2012). Media consumption across platforms: Identifying user-defined repertoires. New Media \& Society, 14(6), 951-968. https://doi.org/ 10.1177/1461444811436146

Taneja, H., Wu, A. X., \& Edgerly, S. (2017). Rethinking the generational gap in online news use: An infrastructural perspective. New Media \& Society, 20(5), 1792-1812. https://doi.org/10.1177/14614448177 07348

Thompson, D. (2018). The media's post-advertising future is also its past. The Atlantic. Retrieved from https://www.theatlantic.com/ideas/archive/2018/ 12/post-advertising-future-media/578917

Thorson, K., \& Wells, C. (2016). Curated flows: A framework for mapping media exposure in the digital age. Communication Theory, 26(3), 309-328. https://doi. org/10.1111/comt.12087

Thurman, N., Moeller, J., Helberger, N., \& Trilling, D. (2018). My friends, editors, algorithms, and I. Digital Journalism, 7(4), 447-469. https://doi.org/10.1080/ 21670811.2018.1493936

Tracy, M. (2019, November 19). Gannett, now largest U.S. newspaper chain, targets 'inefficiencies.' The New York Times. Retrieved from https://www.nytimes. com/2019/11/19/business/media/gannettgatehouse-merger.html

Uberti, D. (2019). BuzzFeed and the digital media meltdown. Columbia Journalism Review. Retrieved from https://www.cjr.org/business_of_news/buzzfeedfuture-jonah-peretti-union.php

Usher, N. (2014). Making news at The New York Times. Ann Arbor, MI: University of Michigan Press.

Webster, J. G. (2014). The marketplace of attention. Cambridge, MA: MIT Press.

Webster, J. G., \& Ksiazek, T. B. (2012). The dynamics of audience fragmentation: Public attention in an age of digital media. Journal of Communication, 62(1), 39-56. https://doi.org/10.1111/j.1460-2466. 2011.01616.x

Yang, J. (2015). Effects of popularity-based news recommendations ("most-viewed") on users' exposure to online news. Media Psychology, 19(2), 1-29. https:// doi.org/10.1080/15213269.2015.1006333

\section{About the Author}

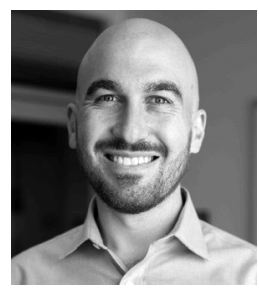

Jacob L. Nelson (PhD, Northwestern University) is an Assistant Professor at the Walter Cronkite School of Journalism and Mass Communication at Arizona State University, and a fellow with Columbia University's Tow Center for Digital Journalism. He uses qualitative and quantitative methods to study the changing relationship between journalism and the public. 